\title{
From sequence of tumor liberated protein (TLP) to potential targets for diagnosis and therapy
}

\author{
Giulio Tarro ${ }^{1,2 *}$ \\ ${ }^{1}$ Foundation T. \& L. de Beaumont Bonelli for cancer research, Naples, Italy \\ ${ }^{2}$ Committee on Biotechnologies and VirusSphere, World Academy of Biomedical Technologies, UNESCO, Paris, France
}

\begin{abstract}
A preliminary analysis of immunoprecipitation followed by Western Blotting (WB) shows corin and TLP precipitate at the same level (approximately $50 \mathrm{KDa}$ ) and are recognized by the same antibodies. In parallel the tests of immunoprecipitation were improved by the use of cell extracts derived from lung cancer cells A549 and NCI-H23 with the aim of obtaining a precipitate containing only the TLP. In fact the partial amino acid sequence of TLP shows a high homology with the sequence of human corin (only one amino acid is different) and is present in lung cancer under different isoforms. It is known that human corin is expressed mostly outside the cells and the protein extract derived from the extracellular medium and from the cells transfected with the plasmid, which overexpresses corin, shows several bands analysed on SDS-PAGE that are equivalent to the bands (about 50-100 KDa) observed in the WB analysed by anti-TLP.
\end{abstract}

\section{Introduction}

While surgery, radiotherapy and chemotherapy are able to cure many cancers, new approaches are required to improve radical curative therapy. A possible route is to utilize the latest achievements made in research on the immunology and genetics of cancer [1]. Cancer immunotherapy [2], or the manipulation of the naturally occurring oncolytic immune reaction, is based on the observation that neoplastic cell antigens stimulate the onset of specific humoral and cellular antibodies both in animals and humans [3]. Certain difficulties that have been encountered reflect the lack of well-purified antigens and/or their ability to unblock cell immunity in the cancer patient.

Two ways are known to enhance the host's immunity: aspecific activation (BCG in primis) and specific activation (to stimulate oncolytic circulating and cell antibodies). Moreover, some researchers have performed therapeutic trials with antigens, from autologous and homologous human cancer cells, obtained by various purification procedures $[4,5]$.

The first observation by Tarro et al. [6] demonstrated that when TLP is extracted from a tumor, purified in the laboratory, and reintroduced into the patients body, it boosts the immune system's cancer responsive capabilities [7]. As lung cancer accounts for the largest number of cancer deaths in the Western world, TLP may have the potential to greatly improve the cure rate and or serve as a lung cancer vaccine (Table 1) [8].

Corin is a cardiac serine protease that activates natriuretic peptides.

Table 1. Tumor liberated protein from lung cancer and perspectives for immunotherapy.

\begin{tabular}{|l|}
\hline TLP AS A TUMOR-ASSOCIATED ANTIGEN \\
\hline TUMORS AND OTHERS EPITHELIAL \\
ADENOCARCINOMAS \\
\hline - IMMUNIGENIC IN HUMANS AS EVIDENCED BY \\
SERUM ANTIBODIES
\end{tabular}

It consists of an $\mathrm{N}$-terminal cytoplasmic tail, a transmembrane domain, and an extracellular region with a C-terminal trypsin-like protease domain. The transmembrane domain anchors corin on the surface of cardiomyocytes. To date, the function of the corin cytoplasmic tail remains unknown [9]. Corin shows high homology with TLP and is present in various isoforms in the lung [10. If the fragments cut with thrombin proved to be the same, the data would support the hypothesis that TLP and corin are the same protein. At the same time a plasmid was used that allows us to transfect and over-express human corin with the purpose of assessing whether the two proteins are actually the same protein or are different by Western blotting (using anti-TLP and anticorin antibodies).

\section{Materials and methods}

\section{Antigen synthesis and antibody production}

The synthesis of the TLP-derived peptide RTNKEASI [23] and two different rabbit polyclonal anti-RTNKEASI immune sera were carried out at Rockland Immunochemicals Inc. (Gilbertsville, PA, USA) and at Biogenes $\mathrm{GmbH}$ (Berlin, Germany). The serum anti-TLP produced at Rockland was further purified against RTNKEASI peptide by chromatography.

\section{Cell culture}

The human cell lines A549, CA46, HL60, MCF7, MRC-5, Hela and PC3 were obtained from American Type Culture Collection (ATCC; Manassas, VA, USA). A549, MRC-5, HL60, Hela, and MCF7 cell lines were cultured in Glutamax Dulbecco's Modified Eagle's

Correspondence to: Giulio Tarro, Via Posillipo 286, 80123 Naples, Italy; E-mail: gitarro@tin.it; giuliotarro@gmail.com

Key words: TLP, NSCLC, corin, immunotherapy, vaccine

Received: May 19, 2017; Accepted: June 13, 2017; Published: June 15, 2017 
Medium (Gibco, life technologies), CA46 cell line in Glutamax RPMI 1640 (Gibco, life technologies), and PC-3 cell line in Glutamax HAM's F-12 (Gibco, life technologies), supplemented with $10 \%$ fetal bovine serum (Biochrom $\mathrm{GmbH}$, Berlin, Germany) at $37^{\circ} \mathrm{C}$ in a humidified atmosphere of $5 \% \mathrm{CO}_{2}$ in air, according to the ATCC recommendations.

\section{Western blot}

Cell pellets were prepared from A549, CA46, HL60, MCF7, MRC5, Hela and PC3 cell lines and lysed as described previously.

Cell culture supernatant from $5 \times 10^{6}$ A549 cells was incubated with ice-cold $10 \%$ trichloroacetic acid (TCA) on ice for $30 \mathrm{~min}$ and then centrifuged at $4^{\circ} \mathrm{C}$ at $14000 \mathrm{rpm}$ for $30 \mathrm{~min}$. The pellet was incubated with ice-cold $90 \%$ aceton at $-20^{\circ} \mathrm{C}$ for $20 \mathrm{~min}$. After centrifugation, the pellet was dried at $65^{\circ} \mathrm{C}$ for $30 \mathrm{~min}$.

Proteins $(30 \mu \mathrm{g})$ were resuspended in $4 \mathrm{X}$ Laemmli sample buffer (100 mM Tris-HCl, $\mathrm{pH}$ 6.8, 4\% sodium dodecyl sulfate (SDS), $20 \%$ glycerol, $200 \mathrm{mM}$ dithiothreitol (DTT) and $0.01 \%$ bromophenol blue), boiled for $5 \mathrm{~min}$ and resolved by $8 \%$ acrylamide (Applichem $\mathrm{GmbH}$, Darmstadt, Germany) SDS-PAGE gel. The proteins were blotted onto activated polyvinylidene difluoride (PVDF) membranes (Millipore, Bedford, Mass), which were incubated in blocking buffer (nonfat dry milk $8 \%+$ PBS $+0.1 \%$ Tween-20) and then probed overnight at $4^{\circ} \mathrm{C}$ with the anti-RTNKEASI serum 1:1000 (Biogenes, Berlin, Germany; Rockland Immunochemicals, PA, USA) or B-actin 1:20000 (Biolegend, San Diego, CA). After $1 \mathrm{~h}$ of incubation with the corresponding horseradish peroxidase-conjugated secondary antibody diluted 1:30000 in PBS + 0,1\% Tween-20 + BSA 5\%, the immunoreactive bands were detected by enhanced chemiluminescence (GE Healthcare, Little Chalfont, UK).

\section{Peptide competition assay (PCA)}

The anti-RTNKEASI serum was diluted 1:1000 in PBS $+0,1 \%$ Tween-20 + BSA 5\% buffer and pre-incubated with a 500-fold molar excess of the peptide RTNKEASI or with control peptide KDSGNEQTFLPP for $1 \mathrm{~h}$ at room temperature followed by $1 \mathrm{~h}$ at $37^{\circ} \mathrm{C}$ with gentle rocking. The pre-incubated antibody samples were cleared from immune complexes by centrifugation and subsequently hybridized for 2 hours with A549 lysates transferred on PVDF membranes. After wash with PBS $0,1 \%$ + Tween-20 to remove unbound antibody, the membranes were processed according to the conventional western blot method.

\section{Two-dimensional polyacrylamide gel electrophoresis}

Protein extraction from A549 and MCF7 cell lines was performed as described previously. The first dimension isoelectric focusing was performed by using $7 \mathrm{~cm}$ immobilized $\mathrm{pH}$ gradient (IPG) dry strips with a linear $\mathrm{pH}$ 4-7 gradient (GE Healthcare). $50 \mu \mathrm{g}$ of solubilized proteins were applied onto the strips in rehydration buffer $(8 \mathrm{M}$ urea, $2 \mathrm{M}$ thiourea, 2\% 3-[(3-cholamidopropyl) dimethylammonio]1-propanesulfonate (CHAPS), $50 \mathrm{mM}$ DTT with $0.5 \%$ IPG buffer) with $1 \mu \mathrm{l}$ bromophenol blue $1 \%$ and incubated over night at room temperature. Proteins were separated by the PROTEAN IEF system (Bio-Rad) using a programmed voltage gradient at $20^{\circ} \mathrm{C}$ with a current limit of $50 \mu \mathrm{A}$ per strip in the dark under the following conditions: $4 \mathrm{~h}$ at $250 \mathrm{~V}, 8000 \mathrm{~V}$ linear gradient to $15000 \mathrm{Vh}$, rapid $8000 \mathrm{~V}$ to 75000 $\mathrm{Vh}$, for a total of $90 \mathrm{kVh}$. The first dimension strip was equilibrated in buffer A (0.05M Tris-HCl, $6 \mathrm{M}$ urea, 20\% glycerol, 2\% SDS and 130 mM DTT) and buffer B containing $4.5 \%$ iodoacetamide instead of DTT for 10 minutes. For the second dimension, the equilibrated strips were applied to the top of $8 \%$ acrylamide (Applichem GmbH, Darmstadt, Germany) SDS-PAGE gel and sealed with $1 \%$ agarose prepared in SDS-Tris-glycine buffer with traces of BPB as a tracking dye to monitor electrophoresis. The resolved proteins were visualized directly by silver staining or transferred to a PVDF membrane (Millipore, Bedford, Mass) and incubated with the anti-RTNKEASI serum, according to the western blot procedure.

\section{Results}

Western blotting shows that Corin and TLP seem to precipitate at the same level (approximately $50 \mathrm{KDa}$ ) and are recognized by the same antibodies. Concurrently a plasmid was obtained from Prof, Qingyu (Cleveland, Ohio) that transfects HEK-293 cells and overexpress the human corin with the purpose of evaluating whether the two proteins are really the same proteins by Western blotting (using anti-TLP and anti-corin). In parallel the tests of immunoprecipitation were improved by the use of cell extracts derived from lung cancer cells A549 and NCI-H23 with the aim of obtaining a precipitate containing only the TLP. This result would allow a better sequence of the aminoterminal fragment of TLP and furthermore would allow to look in details the homologies between TLP and corin.

From a careful analysis of bibliography concerning both TLP and Human corin, analysed by Mass Spectrometry (in preparation) and from our data, TLP is present in more quantity within the cell and with more specificity in the non small cell lung cancer than in the small cell lung cancer as corin.

In fact the partial amino acid sequence of TLP shows a high homology with the sequence of human corin (only one amino acid is different) and is present in lung cancer under different isoforms. From the literature it is known that human corin is expressed mostly outside the cells and the protein extract derived from the extracellular medium and from the cells transfected with the plasmid, which overexpresses corin, shows a number of bands analyzed on SDS-PAGE that are equivalent to the bands (about 50-100 KDa) observed in the Western blots analyzed using anti-TLP.

Therefore the protein band identified as TLP through mass spectrometry reveales the molecular nature of at least one component of the previously described TLP complex.

\section{Conclusion}

Tumor liberated protein (TLP) is a new protein extracted from tumors in vivo and transformed cells in vitro (Figure 1)[8].

TLP is detectable in blood as well as in cancer tissue [11,12].

TLP is a tumor associated antigen of $50 \mathrm{KD}$ monomer [13,14].

TLP is overexpressed in lung tumor $[13,14]$ and other epithelial adenocarcinomas $[15,16]$.

TLP is immunogenic in humans as evidenced by serum antibodies [17].

Preliminary information on lung tissue microarray is shown in table 2 .

Research is ongoing to obtain the complete sequence of TLP, by proteomics approaches, in order to achieve adequate antigen preparations that might be used to generate assays for early diagnosis and, possibly, a specific anticancer vaccine [18].

The perspectives of TLP are the following: 
Table 2. Sensitivity and specificity of TLP for antibodies.

\begin{tabular}{|c|c|c|}
\hline \multicolumn{3}{|c|}{ TISSUE MICROARRAY PROFILE (a) } \\
\hline NSCLC STAGE I & $\begin{array}{c}\text { POSITIVITY } \\
(\%)\end{array}$ & $\begin{array}{c}\text { NEGATIVITY } \\
\text { TISSUE }\end{array}$ \\
\hline 400 & 56.3 & 43.7 \\
& $(225 / 400)$ & $(175 / 400)$ \\
\hline NORMAL LUNG & POSITIVITY & NEGATIVITY \\
TISSUE & $(\%)$ & $(\%)$ \\
\hline 400 & 0 & 100 \\
& $(0 / 400)$ & $(400 / 400)$ \\
\hline
\end{tabular}

(a) Carried out by William C. Hyun, Ph.D., at the University of California San Francisco, Cancer Center, Laboratory Cell Analysis.

- $\quad$ Since its sequences stimulate cytotoxic immunoresponse in humans and animal models, it is possible to design potential active and passive immunotherapies for non small cell lung cancer (NSCLC) and colorectal cancers (CRC) based on TLP epitopes and humanized antibodies $[19,20$.

- Fragments of TLP can be used to stimulate immune response to attack existing tumors $[9,21]$.

- At risk populations could be inoculated with TLP fragments to stimulate immune response to undetected or newly developing tumors [22,23].

- Therefore the ability of the immune system to recognize TLP represents a main target for diagnosis and therapy in this field of research.

\section{Conflict of interest statement}

The author declares no conflict of interest.

\section{References}

1. Finn OJ (2008) Cancer immunology. N Engl J Med 358: 2704-2715. [Crossref]

2. Benjamini E, Rennick DM (1979) Cancer immunotherapy: facts and fancy. CA Cancer J Clin 29: 362-370. [Crossref]

3. Weiss DW (1980) Tumor antigenicity and approches to tumor immunotherapy. An outline In: current topics in microbiology and immunology. Berlin, Heidelberg, New York: Springer Verlag.

4. Hollinshead A, McCammon JR, Yohn DS (1972) Immunogenecity of a soluble transplantation antigen from adenovirus 12 - induced tumor cells demostrated in inbred hamsters (PD-4). Can J Microbiol 18: 1365-1369.

5. Prager MD (1973) Immunity induction by multiple methods, including soluble membrane fractions to a mouse lymphoma. J Natl Cancer Inst 51: 1607.
6. G. Tarro, A. Pederzini, G. Flaminio, S. Maturo. Human tumor antigens inducing in vivo delayed hypersensitivity and in vitro mitogenic activity. Oncology 40: 248-254. 1983.

7. 7. G. Tarro. Present and future of cancer immunotherapy: A. Sagripanti, C. Gagliardi, A. Carpi. G. Tarro. , editors. Progress in Medicine and Surgery, Proc. Nat. Meeting, San Romano (Pisa) 13 April 1991, 181-186 ETS, Publisher, Pisa. 1991.

8. Tarro G (2009) Tumor liberated protein from lung cancer and perspectives for immunotherapy. J Cell Physiol 221: 26-30. [Crossref]

9. Wu F, Wu Q (2003) Corin-mediated processing of pro-atrial natriuretic peptide in human small cell lung cancer cells. Cancer Res 63: 8318-8322. [Crossref]

10. Qi X, Jiang J, Zhu M, Wu Q (2011) Human corin isoforms with different cytoplasmic tails that alter cell surface targeting. The Journal of Biological Chemistry 286: 20963 20969. [Crossref]

11. Tarro G, Esposito C (2002) Progress and new hope in the fight against cancer: nove developments in early detection of lung cancer. Int Med 10: 7-11.

12. Tarro G, Perna A, Esposito C (2005) Early diagnosis of lung cancer by detection of tumor liberated protein. J Cell Physiol 203: 1-5. [Crossref]

13. Tarro G, Marshak DR, Perna A, Esposito C (1993) Antigenic regions of tumor liberated protein complexes and antibodies against the same. In: A. Carpi, A. Sagripanti, B. Grassi, editors. Third International Congress. Advances in Management of Malignancies. Pisa, Italy: 6/10 December 1993. Biomed \& Pharmacother 47: 237-240.

14. Tarro G, Esposito C, Perna A, Claudio PP, Giordano A, et al. (1998) Immunoistochemical characterization of tumor liberated particles (TLP) expression pattern in lung cancer. Anticancer Res 18: 2365-2370. [Crossref]

15. Guadagni F, Graziano P, Roselli M, Mariotti S, Bernard P, et al. (1999) Differential expression of a new tumor-associated-antigen TLP during human colorectal cancer tumorigenesis. Am J Pathol 154:993-999. [Crossref]

16. Rasi G, Sinibaldi-Vallebona P, Serafino A, Bernard P, Pierimarchi P, et al. (2000) A new human tumor-associated antigen (TLP) is naturally espressed in rat DHD-K12 colorectal tumor cells. Int J Cancer 85: 540-544.

17. Esposito C, Tarro G, Cuomo N, Morelli F (1997) Anti-TLP antibodies in lung cancer patients. Int Med 5: 191-194.

18. Indovina P, Marcelli E, Maranta P, Tarro G (2011) Lung cancer proteomics: recent advances in biomarker discovery. Int J Proteomics 2011: 726869. [Crossref]

19. Herberman RB (1997) Immunotherapy: where we are and how to proceed. In: Croce CM Doctor's Acta 14-15.

20. Tarro G (1999) Tumor liberated protein (TLP): its potential for diagnosis and therapy. Anticancer Res 19: 1755-1757. [Crossref]

21. Bernard P, Sinibaldi-Vallebona P, Rasi G, Guarino, Guadagni F, et al. (1998) Immunisation with TLP (A new Tumor Associated Antigen) induces CTL activity in syngeneic rats. Anticancer Res 18: 4990-4994

22. Tarro G (2000) An overview of the lung tumor liberated protein (TLP).Characterization of the genetic immunologic profile. Int Med 8: 5-8.

23. Tarro G (2002) Characterization of a fragment containing a putative TLP cDNA sequence. Anticancer Res 22: 2693-2696. [Crossref]

Copyright: (C2017 Tarro G. This is an open-access article distributed under the terms of the Creative Commons Attribution License, which permits unrestricted use, distribution, and reproduction in any medium, provided the original author and source are credited. 